\title{
Versican V1 in human endometrial epithelial cells promotes BeWo spheroid adhesion in vitro
}

\author{
Yumiko Miyazaki , Akihito Horie ${ }^{1}$, Hirohiko Tani ${ }^{1}$, Masashi Ueda ${ }^{1}$, Asuka Okunomiya ${ }^{1}$, \\ Koh Suginami ${ }^{1}$, Eiji Kondoh¹, Tsukasa Baba ${ }^{1}$, Ikuo Konishi², Tamayuki Shinomura ${ }^{3}$ \\ and Yukiyasu Sato ${ }^{4}$ \\ ${ }^{1}$ Department of Gynecology and Obstetrics, Kyoto University Graduate School of Medicine, Kyoto, Japan, \\ ${ }^{2}$ Department of Obstetrics and Gynecology, National Hospital Organization Kyoto Medical Center, Kyoto, Japan, \\ ${ }^{3}$ Tissue Regeneration, Department of Bio-Matrix, Tokyo Medical and Dental University, Bunkyo, Japan and \\ ${ }^{4}$ Department of Obstetrics and Gynecology, Otsu Red Cross Hospital, Otsu, Japan \\ Correspondence should be addressed to A Horie; Email: a_horie@kuhp.kyoto-u.ac.jp
}

\begin{abstract}
The endometrium extracellular matrix (ECM) is essential for embryo implantation. Versican, a large chondroitin sulfate proteoglycan that binds hyaluronan and forms large ECM aggregates, can influence fundamental physiological phenomena, such as cell proliferation, adhesion and migration. The present study investigated the possible role of versican in human embryo implantation. Versican V1 expression and secretion in human endometrial epithelial cells (EECs) was most prominent in the mid-secretory phase. Versican expression in EECs significantly increased after treatment with estrogen and progesterone, but not by estrogen alone. We also established versican V1-overexpressing Ishikawa (endometrial cancer cell line) cells (ISKW-V1), versican V3-overexpressing (ISKW-V3) and control GFP-overexpressing (ISKW-GFP) Ishikawa cells. By the in vitro implantation model, the attachment ratio of BeWo (choriocarcinoma cell line) spheroids to the monolayer of ISKW-V1, but not of ISKW-V3, was found significantly enhanced compared with attachment to the ISKW-GFP monolayer. The conditioned medium derived from ISKW-V1 (V1-CM) also promoted the attachment of BeWo spheroids to the ISKW monolayer. However, this attachment-promoting effect was abolished when V1-CM was pretreated with chondroitinase $\mathrm{ABC}$, which degrades chondroitin sulfate. Therefore, out of the ECM components, versican $\mathrm{V} 1$ may facilitate human embryo implantation.

Reproduction (2019) 157 53-64
\end{abstract}

\section{Introduction}

Improvements in in vitro fertilization, embryo transfer and laboratory techniques have resulted in increased pregnancy rates, yet implantation rates remain disappointingly low (Ng et al. 2018). The extracellular matrix (ECM) of the endometrium plays critical roles in the process of embryo implantation (Salgado et al. 2009). Endometrial ECMs are predominantly composed of collagens, non-collagenous multiadhesive glycoproteins (e.g., fibronectin, laminin and vitronectin), elastin, hyaluronan and proteoglycans (Kresse \& Schonherr 2001). Fibronectin, laminin and collagen type IV defects in human endometrium are associated with endometrial dysfunction and implantation failure (Bilalis et al. 1996). Hyaluronan is abundant in secretory fluid of the reproductive tract in humans (Chun et al. 2016) and its synthesis increases during the implantation window (Afify et al. 2006). Moreover, hyaluronan promotes bovine embryo development and implantation in vitro (Stojkovic et al. 2002, Lane et al. 2003). The beneficial effects of hyaluronan during human embryo implantation are also substantiated by a recent Cochrane review showing that clinical pregnancy rates are significantly higher when a hyaluronan-rich medium is used for embryo transfer (Bontekoe et al. 2014). Proteoglycans are classified into four groups according to their localization as they can be intracellular, on the cell surface (transmembrane or GPI-anchored), pericellular or extracellular (hyalectan or small leucine-rich proteoglycans; lozzo \& Schaefer 2015). Heparan sulfate proteoglycans are expressed on the surface of peri-implantation murine embryos and promote their initial attachment to the uterine epithelia (Carson et al. 1994, San Martin et al. 2004); they have also been shown to mediate attachment of JAR cells (human choriocarcinoma cell line) to monolayers of RL95-2 cells (human endometrial cancer cell line; (Rohde \& Carson 1993), suggesting their supportive roles in human embryo implantation.

Versican belongs to the hyalectan family (named for their ability to bind hyaluronan; (Wight 2002), is a chondroitin sulfate proteoglycan and was originally 
isolated from developing chicken limb buds (Kimata et al. 1986) and human fibroblasts (Naso et al. 1994). Twelve to fifteen chondroitin sulfate side chains are covalently bound to glycosaminoglycan (GAG)- $\alpha$ and GAG- $\beta$ domains encoded by exons 7 and 8 , respectively. Alternative splicing of exon 7 and/or exon 8 generates four isoforms, V0, V1, V2 and V3. Versican $\vee 0$, the largest isoform, contains both GAG- $\alpha$ and GAG$\beta$ domains, whereas versican $\mathrm{V} 1$ and $\mathrm{V} 2$ lack GAG- $\alpha$ and GAG- $\beta$, respectively. Versican $V 3$, the shortest isoform, does not contain either of the GAG domains and is consequently devoid of chondroitin sulfate side chains (Dours-Zimmermann \& Zimmermann 1994, Zako et al. 1995). All versican isoforms contain globular domains at the $\mathrm{N}$-terminus (G1) and C-terminus (G3). The G1 domain interacts with hyaluronan, the G3 domain interacts with integrin $\beta 1$, and the GAG domains interact with CD44 and selectins (Wu et al. 2005). By interacting with these molecules, versican plays many pivotal roles in regulating variable cellular processes including adhesion, proliferation, apoptosis, migration and invasion (Wight 2002, Wight et al. 2014). Recently, Tani et al. (2016) demonstrated that versican is upregulated in the macroscopically normal peritonea of women with peritoneal endometriosis compared to those without. In vitro, versican promotes the attachment of endometrial stromal cells (ESCs) to the monolayer of peritoneal cells as well as the invasion of ESCs through the basement membrane (Tani et al. 2016). Based on these findings, we propose that versican may be involved in human embryo implantation.

Although it has been reported that versican is expressed in both murine (Salgado et al. 2009) and human endometria (Yamaguchi et al. 2006), the specific expression and function of versican isoforms in the human endometrium has not been fully elucidated. It is both technically and ethically problematic to examine the process of human embryo implantation in vivo. To overcome this formidable barrier, several experimental models have been developed to reproduce the process of human embryo implantation in vitro. Since the availability of human blastocysts is extremely limited and primary endometrial cells are susceptible to interindividual variations, such as age, menstrual cycle phase and genetic background, cell line in vitro models have been commonly used to investigate the process of human embryo implantation (Heneweer et al. 2005, Uchida et al. 2012). We utilized an in vitro embryo implantation model consisting of an endometrial cancer cell line (Ishikawa), which retains the characteristics of normal endometrial cells (Hannan et al. 2010, Nishida 2002), and a choriocarcinoma cell line (BeWo), which shares similar characteristics with undifferentiated trophoblasts of blastocysts (Hamilton 1998). The purpose of this study was to investigate the function of versican during human embryo implantation by employing our in vitro implantation model.

\section{Materials and methods}

\section{Antibodies and reagents}

Antibodies used in this study are listed in Supplementary Table 1 (see section on supplementary data given at the end of this article). Goat anti-human versican polyclonal antibody (pAb; \#AF3054), which recognizes an amino acid sequence in the GAG- $\beta$ domain specific to the V0 and V1 isoforms, was purchased from R\&D Systems. Mouse anti-human versican monoclonal antibody ( $\mathrm{mAb}$; clone 2B1, \#270428) recognizing the amino acid sequence in the C-terminal G3 domain common to all isoforms (Sobue et al. 1989, Isogai et al. 1996) was purchased from Seikagaku Corp. (Tokyo, Japan). Rabbit anti-human versican pAb (\#HPA004726), which recognizes the amino acid sequence in the $\mathrm{N}$-terminal G1 domain common to all isoforms, was obtained from Sigma-Aldrich. Normal goat immunoglobulin G (IgG) for negative control (\#sc-2028) and horseradish peroxidase (HRP)-conjugated goat anti-rabbit $\operatorname{lgG}$ ( $\mathrm{pAb}$; \#sc-2054) were obtained from Santa Cruz Biotechnology. FITC-conjugated rabbit anti-goat IgG (pAb; \#F0250), TRITC-conjugated swine anti-rabbit IgG (pAb; \#R0156), HRP-conjugated rabbit anti-goat IgG (pAb; \#P0449) and HRP-conjugated goat anti-mouse IgG (pAb; \#P0447) were purchased from Dako Denmark A/S.

\section{Tissue samples}

Human endometrial tissue samples were obtained from normally cycling women aged 28-45 years who had undergone therapeutic hysterectomies for the treatment of benign uterine diseases or cervical carcinomas in situ. None of the patients were treated with hormonal medication or contraceptive pills for at least 3 months prior to surgery. According to the Declaration of Helsinki, informed consent for the use of these tissues was obtained from each donor. The use of the samples was approved by the Ethics Committee of Kyoto University Hospital.

\section{Immunohistochemical staining}

Endometrial samples were histologically staged according to the criteria of Noyes (Noyes et al. 1975) and were classified as early proliferative ( $n=2$; cycle days $5-7)$, mid-proliferative $(n=2$; cycle days $8-10)$, late proliferative $(n=2$; cycle days $11-14)$, early secretory ( $n=6$; cycle days $15-19)$, mid-secretory $(n=6$; cycle days 20-24) and late secretory $(n=6$; cycle days 25-28) phases. Immunohistochemistry was performed as described previously (Tani et al. 2016). Briefly, formalinfixed, paraffin-embedded tissue sections prepared from whole endometria were immunostained with the streptavidin-biotin complex peroxidase method with 3,3'-diaminobenzidine tetrahydrochloride (DAB) as the chromogen. Sections were subjected to an antigen-retrieval technique with the Histofine SAB-PO Kit (Nichirei Biosciences, Tokyo, Japan) and treated with goat anti-human versican $\mathrm{pAb}$ specific for the versican $\mathrm{V} 0$ and $\mathrm{V} 1$ isoforms or normal goat $\lg \mathrm{G}$ as negative control. Immunostaining intensities of versican in endometrial epithelial cells (EECs) and ESCs were separately assessed by an independent blinded observer using a semi-quantitative 
scoring system as follows, 0 , negative; 1 , very weak; 2 , weak; 3, moderate; 4, strong; 5, very strong.

\section{Isolation of EECs and ESCS}

EECs and ESCs were isolated from endometrial tissues as described previously (Kosaka et al. 2003). Small pieces of minced endometrial tissue $\left(<1 \mathrm{~mm}^{3}\right)$ were digested enzymatically with $0.2 \%$ collagenase (Sigma-Aldrich) and $0.005 \%$ DNase (Sigma-Aldrich). ESCs were then purified using differential gravitational sedimentation (Kariya et al. 1991) and seeded onto a 10-cm tissue culture dish (Corning Inc.). The larger clumps containing EECs were digested again with collagenase and DNase and were then allowed to attach onto a $10 \mathrm{~cm}$ cell culture dish for $1 \mathrm{~h}$ at $37^{\circ} \mathrm{C}$ to remove adherent ESCs. Non-adherent clumps were collected and treated with $0.05 \%$ trypsin (Gibco) and $0.02 \%$ EDTA (Nakalai, Kyoto, Japan) to obtain isolated EECs. EEC preparation purity was greater than $95 \%$, as they were positive for CD9 (endometrial epithelial cell marker) and negative for both CD13 (endometrial stromal cell marker) and CD45 (leukocyte marker; (Kosaka et al. 2003).

\section{Immunocytochemistry}

EECs were isolated from proliferative-phase endometria $(n=5$; cycle days 7-13) as described above. Isolated EECs $\left(5 \times 10^{5}\right.$ cells) in $2 \mathrm{~mL}$ of phenol red-free MEM plus $10 \%$ fetal bovine serum (FCS) that had been pretreated with dextran-coated charcoal (Sigma-Aldrich) were plated on a 35-mm cell culture plate (Greiner Bio-One, Frickenhausen, Germany). After a 24 or 72-h incubation period, immunocytochemical staining was performed on cultured EECs treated with goat anti-human versican $\mathrm{pAb}$ or normal goat IgG using standard protocols. FITC-conjugated rabbit anti-goat secondary antibody was used for detection.

\section{Treatment of isolated EECs with ovarian steroids}

EECs $\left(5 \times 10^{5}\right.$ cells in $2 \mathrm{~mL}$ of phenol red-free MEM plus $10 \%$ FCS pretreated with dextran-coated charcoal) isolated from proliferative-phase endometria $(n=5$; cycle days $7-13)$ were plated on a $35-\mathrm{mm}$ round-bottom cell culture plate and incubated for $24 \mathrm{~h}$. Estradiol ( $\mathrm{E}_{2}$; Sigma-Aldrich) at a final concentration of $10 \mathrm{nM}$ with or without progesterone $\left(\mathrm{P}_{4}\right.$; Sigma-Aldrich) at a final concentration of $1 \mu \mathrm{M}$ was added to the medium. The same amount of $99 \%$ ethanol $(\mathrm{EtOH})$, of which the final concentration was $0.1 \%(\mathrm{v} / \mathrm{v})$, was added as control. After $48 \mathrm{~h}$ of incubation, EECs were immunostained with goat anti-human versican $\mathrm{pAb}$ followed by the addition of FITC-conjugated secondary antibody as described earlier. Intensity of the immunoreactive FITC signal was calculated as an integrated density using Image J v1.47 (NIH). The immunostained specimen was divided into five areas (central, upper, lower, right and left) all at a magnification of $100 \times$ and the sum of the integrated densities from the five areas was defined as the versican expression level of the specimen. The result was presented as relative expression levels compared with the control $(\mathrm{EtOH})$.

\section{RT-PCR and real-time PCR}

Total RNA was extracted from whole endometrial tissue using TRIzol reagent (Thermo Fisher Scientific) and then reverse-transcribed with random primers using a First Strand cDNA Synthesis Kit (GE Healthcare). Each PCR product was electrophoresed on a $1.0 \%$ agarose gel and visualized by ethidium bromide staining. Real-time PCR was performed using the Power SYBR Green PCR Master Mix (Life Technologies) and the StepOnePlus Real-Time PCR System (Applied Biosystems). The primers used are shown in Table 1.

\section{Western blotting}

EEC proteins were obtained from ten different patients (five from proliferative endometria and five from secretory endometria; the EEC sample from 'cycle day 3', defined as menstrual phase (Noyes et al. 1950), was histologically compatible with one of the proliferative phase). Versican protein expression was evaluated by western blotting as previously described (Wasa et al. 2012). Briefly, EECs were treated with chondroitinase $\mathrm{ABC}\left(0.1 \mathrm{U} / 50 \mu \mathrm{g}\right.$ protein) at $37^{\circ} \mathrm{C}$ for $45 \mathrm{~min}$ to cleave the chondroitin sulfate side chains covalently bound to the core proteins. The proteins $(15 \mu \mathrm{g})$ were then resolved by $5 \%$ SDSpolyacrylamide gel electrophoresis and transferred to PVDF membranes (Millipore). The membranes were then blocked in Block Ace (Dainippon Pharmaceutics, Osaka, Japan) and incubated with goat anti-human versican pAb or mouse anti-GAPDH mAb. ECL Select Western Blotting System (GE Healthcare) was used for detection.

\section{Spheroid formation of BeWo cells}

BeWo, a cell line established from human choriocarcinoma (Pattillo \& Gey 1968), was obtained from the Japanese Collection of Research Bioresources (JCRB, Osaka, Japan). BeWo cells were incubated in RPMI 1640 medium supplemented with $10 \%$ FCS, $100 \mathrm{U} / \mathrm{mL}$ penicillin and $100 \mu \mathrm{g} /$ $\mathrm{mL}$ streptomycin. Spheroid mass formation of BeWo cells was induced as described previously with slight modifications (Kosaka et al. 2003). BeWo cell suspensions $\left(5 \times 10^{2}\right.$ cells in $50 \mu \mathrm{L}$ of $1 \%$ FCS medium) were transferred to a PrimeSurface (Sumitomo Bakelite, Tokyo, Japan) and incubated for $24 \mathrm{~h}$. This procedure enabled us to obtain a single, uniform-sized $(\sim 250 \mu \mathrm{m})$, multicellular spheroid from each well.

\section{Construction of human versican V1 and V3-overexpressing Ishikawa cells}

Ishikawa, a cell line established from human endometrial cancer, was generously provided by Dr Masato Nishida (Kasumigaura Medical Center, Tsuchiura, Japan). Human versican was stably overexpressed in Ishikawa cells using the Trap-In system, a gene expression system combining promoter trapping and site-specific gene integration methods as previously reported (Shinomura et al. 2008).

First, the Ishikawa cells were infected with the retroviral promoter trap vector (rvPtrap). The rvPtrap vector contains a gene encoding a fusion protein of $\beta$-galactosidase and hygromycin phosphotransferase ( $\beta g y g)$, a splice acceptor 
Table 1 Primers for RT-PCR and real-time PCR.

\begin{tabular}{lll}
\hline Gene & Sequence & Reference \\
\hline RT-PCR & & Cattaruzza et al. (2002) \\
Versican V0 & F-TCAACATCTCATGTTCCTCCC & Cattaruzza et al. (2002) \\
Versican V1 & R-TTCTTCACTGTGGTATAGGTCTA & Cattaruzza et al. (2002) \\
Versican V2 & R-GGCTTTGACCAGTGCGATTAC & Cattaruzza et al. (2002) \\
Versican V3 & F-TCAACATCTCATGTTCCTCCC & Vincent et al. (1993) \\
S26 & R-CCAGCCATAGTCACATGTCTC & \\
Real-time PCR & F-GGCTTTGACCAGTGCGATTAC & Takahashi et al. (2012) \\
Versican V0 & R-CCAGCCATAGTCACATGTCTC & Takahashi et al. (2012) \\
Versican V1 & F-GGTCCGTGCCTCCAAGATGA & Takahashi et al. (2012) \\
Versican V2 & R-TAAATCGGGGTGGGGGTGTT & Takahashi et al. (2012) \\
Versican V3 & F-GCACAAAATTTCACCCTGACATT & Chigusa et al. (2013) \\
GAPDH & F-CTTCTTTAGATTCTGAATCTATTGGATGAC & R-CCCAGTGTGGAGGTGGTCTAC \\
\hline
\end{tabular}

sequence of mouse immunoglobulin (SA), and a chemically synthesized FLP recombinase target sequence (FRT). Since ßgyg does not possess its own promoter, rvPtrap should theoretically be integrated into an active gene in the Ishikawa cell to form hygromycin-resistant colonies. The colonies expressing the highest level of $\beta$-galactosidase were selected as Trap-In platform Ishikawa cells (ISKW).

Next, the plasmid containing the full coding sequence of human versican V1 (pInSRT-hM(V1)), versican V3 (pInSRT-hM(V3)) or GFP as control (pInSRT-GFP) was co-transfected along with the FLP recombinase-expressing pOG44 into ISKW using Lipofectamine 2000 (Invitrogen) according to manufacturer's instructions. All three vectors were originally constructed (Supplementary Table 2). In this way, we established three stable clones expressing versican V1, two stable clones expressing versican V3 and five stable clones expressing GFP by dilution cloning in medium containing $1 \mu \mathrm{g} / \mathrm{mL}$ puromycin (Gibco). After verifying overexpression of the intended molecules by western blotting or immunocytochemistry, we arbitrarily selected a single clone from the versican V1-overexpessing, versican V3-overespressing and GFP-overexpressing clones and designated them ISKW-V1, ISKW-V3 and ISKW-GFP, respectively.

\section{Preparation of conditioned medium derived from ISKW-V1 and ISKW-GFP cells}

To prepare conditioned medium, $1 \times 10^{6}$ cells of ISKW-V1 or ISKW-GFP in $1 \mathrm{~mL}$ of RPMI 1640 supplemented with $1 \%$ FCS were plated in 24-well plates (Corning Inc.). After $24 \mathrm{~h}$ of incubation, the culture medium from ISKW-V1 or ISKW-GFP was retrieved and centrifuged at $400 \times \mathbf{g}$ for $10 \mathrm{~min}$. The supernatant was collected as ISKW-V1 conditioned medium (V1-CM) or ISKW-GFP conditioned medium (GFP-CM) and stored at $-80^{\circ} \mathrm{C}$ until further use.

\section{Attachment assay}

Three sets of attachment assays were carried out. In the first set, ISKW-GFP, ISKW-V1 or ISKW-V3 cells $\left(1 \times 10^{6}\right.$ cells in $1 \mathrm{~mL}$ RPMI 1640 supplemented with 1\% FCS) were seeded onto 24-well plates (Corning Inc.) and incubated for $24 \mathrm{~h}$ to obtain a confluent monolayer. In the second set, ISKW monolayers were cultured in the presence of V1-CM or GFP-CM with $1 \%$ FCS. Chondroitinase ABC $(0.1$ units $/ \mathrm{mL})$ derived from Proteus vulgaris (Sigma-Aldrich), which cleave the core protein-linked chondroitin sulfate side chains, was added to each well and incubated for $2 \mathrm{~h}$. Chondroitinase $\mathrm{ABC}$ has been shown to degrade not only chondroitin sulfate but also hyaluronan (Grondahl et al. 2011). In the third set, to rule out the possible influence of hyaluronan digestion by chondroitinase $A B C$, hyaluronidase (10 units/mL) derived from Streptomyces (Sigma-Aldrich), which can specifically degrade hyaluronan, was added to ISKW confluent monolayers cultured in the presence of V1-CM or GFP-CM.

Ten to fifteen BeWo spheroids were carefully placed into the center of each well and allowed to attach to the monolayer for $1 \mathrm{~h}$. The culture plate was then shaken at $180 \mathrm{rpm}$ for $1 \mathrm{~min}$ using a Multi Shaker MMS (Tokyo Rikakikai, Tokyo, Japan) to remove non-attached BeWo spheroids. The number of BeWo spheroids still attached to the monolayer was manually counted under a phase-contrast microscope (Olympus). A spheroid attachment ratio was calculated as the number of attached spheroids divided by the total number of spheroids plated into the well. Three parallel attachment assays were performed for each experimental condition and the mean spheroid attachment ratio was defined as the spheroid attachment ratio for the experimental condition.

\section{Statistical analysis}

All quantitative experiments were performed at least three times. Data are presented as the mean \pm standard deviation. 
Statistical analysis was performed using StatMate v3.14 (ATOMS, Oita, Japan) and comparisons were performed using unpaired Student's t-tests and one-way analysis of variance (ANOVA) followed by Scheffe's multiple comparison tests as appropriate. For all analyses, $P$ values $<0.05$ were considered statistically significant.

\section{Results}

\section{mRNA and protein expression of versican in the} human endometrium

First, mRNA was extracted from whole human endometria of various menstrual cycle phases and subjected to RT-PCR using isoform-specific primers, revealing that versican isoforms were detectable throughout the menstrual cycle (Fig. 1).

Second, whole endometria of various menstrual cycle phases were immunostained using anti-human versican pAb specific for the $\mathrm{V} 0$ and $\mathrm{V} 1$ isoforms (Fig. 2A). In both luminal and glandular EECs, versican expression was higher during the secretory phases than during the proliferative phases, with the most prominent expression at the mid-secretory phase. Intense versican expression was also observed in the secretory products (Fig. 2A (m)). In contrast, versican expression in ESCs appeared relatively constant throughout the menstrual cycle. Semiquantitative scoring confirmed that the immunointensity scores of EECs were significantly higher in secretory phases than in proliferative phases (Fig. 2B (a)), whereas those of ESCs were relatively constant throughout the menstrual cycle (Fig. 2B (b)).

Finally, proteins extracted from isolated EECs were subjected to western blotting using the same antibody used for immunohistochemistry. Ten EEC samples from different patients ( 5 from proliferative endometria and 5 from secretory endometria) were used. Several proteins with different signal intensities ranging from 440 to $500 \mathrm{kDa}$, which are likely to correspond to the V1 isoform, were detected (Fig. 3A). The signal intensities of these proteins were significantly higher in secretoryphase EECs than in proliferative-phase EECs (Fig. 3B).

\section{Secretion of versican from cultured EECS}

EECs isolated from proliferative-phase endometria were seeded on a tissue culture plate. After $24 \mathrm{~h}$ (day 1) or $72 \mathrm{~h}$ (day 3) of culturing, EECs were fixed with paraformaldehyde and immunostained using anti-versican pAb specific for the V0 and V1 isoforms. Theoretically, the antibody cannot pass through the paraformaldehyde-fixed cytoplasmic membrane; therefore, immunocytochemistry assays can only detect versican that was secreted from the EECs and was located on the cell surface or in the extracellular space. As shown in Fig. 4A, versican deposition in the extracellular space markedly increased after $72 \mathrm{~h}$ of incubation.
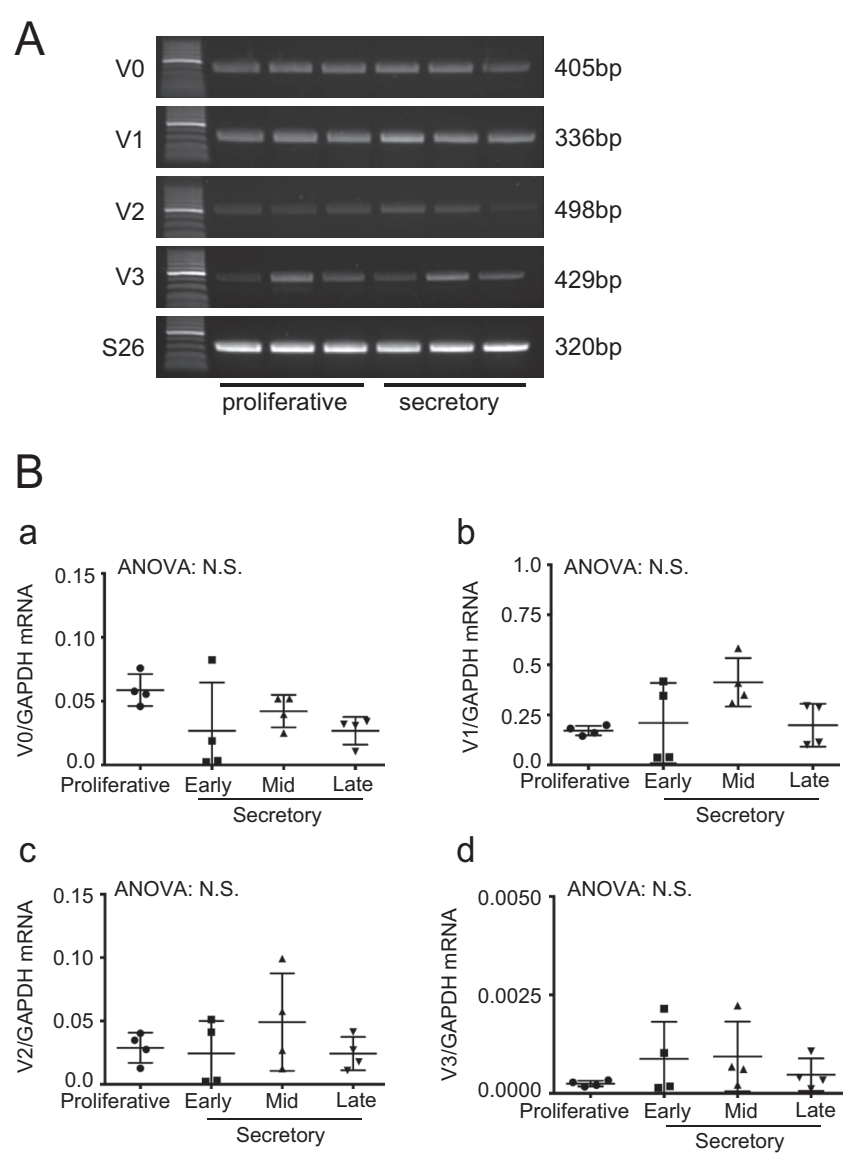

Figure $1 \mathrm{mRNA}$ expression pattern of versican in human endometrium. (A) RT-PCR analysis shows that all versican isoforms (V0-V3) are detected in human endometrial tissue throughout the menstrual cycle. (B) Expression of versican (a) V0, (b) V1, (c) V2 and (d) V3 across different phases of the menstrual cycle was analyzed by quantitative RT-PCR (proliferative, $n=4$; early secretory, $n=4$; mid-secretory, $n=4$; late secretory, $n=4$ ). One-way ANOVA was used for statistical analysis.

\section{Estradiol and progesterone upregulate versican secretion from EECs}

EECs isolated from proliferative-phase endometrial tissues $(n=5)$ were treated for $48 \mathrm{~h}$ with ethanol $(\mathrm{EtOH})$ as control, estradiol alone $\left(\mathrm{E}_{2}\right)$ or estradiol and progesterone $\left(E_{2}+P_{4}\right)$. The amount of versican secreted from cultured EECs was evaluated by immunocytochemistry and as shown in Fig. 4B, versican expression levels were significantly higher in the $\mathrm{E}_{2}+\mathrm{P}_{4}$ group than in the EtOH or $\mathrm{E}_{2}$ groups.

\section{Characterization of ISKW-V1 and ISKW-V3}

The plasmid containing the full coding sequence of human versican V1, versican V3 or control GFP was transfected into Ishikawa cells to generate the V1, V3 and GFP-overexpressing cells; note that versican V3 is devoid of chondroitin sulfate side chains, which 


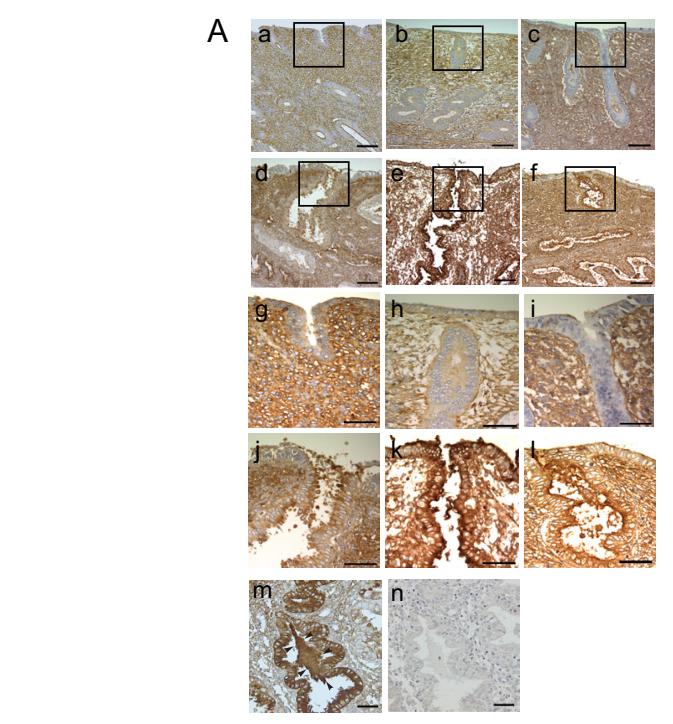

B

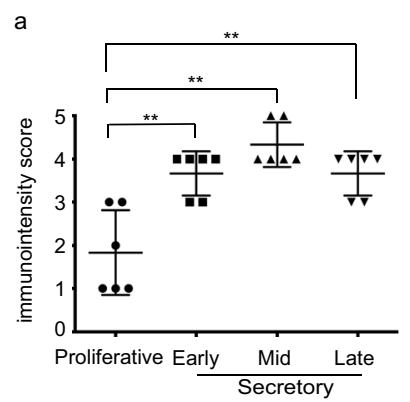

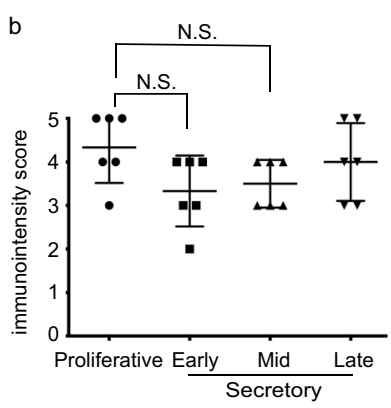

Figure 2 Versican protein expression in human endometrium. (A) Endometrial tissues of various menstrual cycle phases were immunostained with anti-versican polyclonal antibody specific for the V0 and V1 isoforms. (a) Early proliferative phase, (b) midproliferative phase, (c) late proliferative phase, (d) early secretory phase, (e) mid-secretory phase, (f) late secretory phase; (g)-(I) are higher magnification views of the area indicated in (a)-(f), respectively. $(\mathrm{m})$ Glandular epithelium in the functional layer of mid-secretory endometrium. (n) Negative control for $(\mathrm{m})$ in which the anti-versican antibody was replaced by isotype-matched control antibody. Versican expression was detected in both endometrial epithelial cells (EECs) and endometrial stromal cells (ESCs) throughout the menstrual cycle. The intensity of EEC versican expression was higher in the secretory phases than in the proliferative phases. Note that intense versican expression was also detected in intra-glandular products secreted from EECs and are indicated by arrowheads in (m). Scale bars $=100 \mu \mathrm{m}$ in (a)-(f); $50 \mu \mathrm{m}$ in $(\mathrm{g})-(\mathrm{n})$. (B) Signal intensities of versican $\mathrm{V} 1$ were assessed in the immunohistochemical images of whole endometria of various menstrual cycle phases (representative images shown in A). Immunointensity scores ( 0 , negative; 1 , very weak; 2, weak; 3, moderate; 4, strong; 5, very strong) were separately given to (a) EECs and (b) ESCs. Note that immunointensity scores of (a) EECs were significantly higher in the secretory phases than in the proliferative phases, whereas those of (b) ESCs were constant throughout the menstrual cycle. In all panels, error bars represent the standard deviation. ${ }^{*} P<0.05$; ${ }^{* *} P<0.01 ;$ N.S., not significant.
A

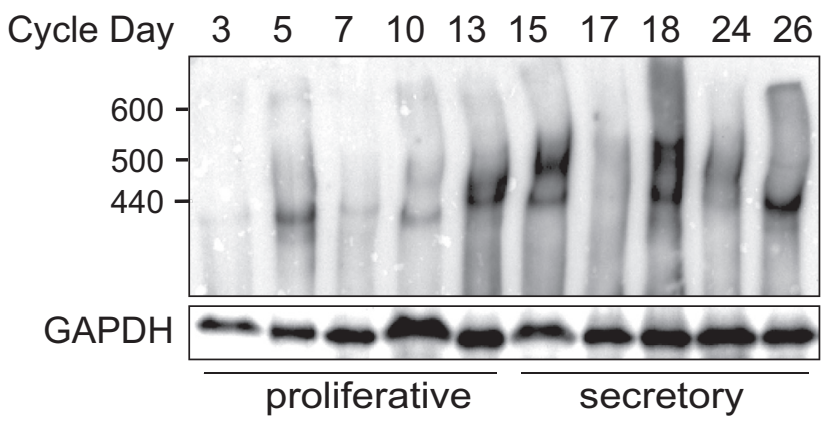

B

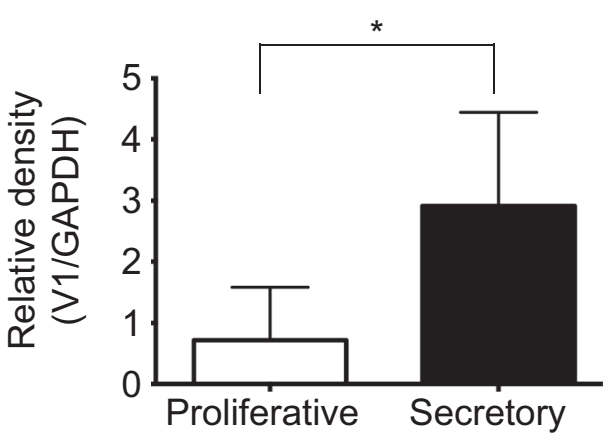

Figure 3 Cyclic changes in versican expression in human endometrium. (A) Lysates of isolated EECs were subjected to western blotting using the same anti-versican antibody as in Fig. 2A, which is specific for versican V0 and V1. The lower panel shows GAPDH as control. Versican $\mathrm{V} 1$ was detected as multiple protein signals ranging from 440 to $500 \mathrm{kDa}$. (B) Protein signal intensities for versican V1 were significantly higher in secretory phases than in proliferative phases. Error bars represent standard deviation. ${ }^{*} P<0.05$.

occur in versican V1. Western blotting showed that immunoreactive versican V1 was detected in the cell lysates (Fig. 5A) as well as the conditioned medium (Fig. 5B) derived from ISKW-V1. On the other hand, versican $\mathrm{V} 3$ was only detectable in the cell lysates derived from ISKW-V3 (Fig. 5C and D). Immunocytochemistry revealed that a large amount of versican $\mathrm{V} 1$ and versican V3 was secreted from ISKW-V1 and ISKW-V3, respectively (Fig. 5E and F). Notably, versican V1 expression was not only detected on the cell surface but also in the extracellular space, whereas versican V3 was only detectable on the cell surface, which is in agreement with the data in Fig. 5B and D.

\section{Versican V1, but not versican V3, promotes BeWo spheroid attachment to ISKW monolayers}

Attached and non-attached BeWo spheroids to the ISKW monolayers were easily distinguishable under a phase-contrast microscope (Fig. 6A). The number of BeWo spheroids directly attached to the ISKW-V1 
A
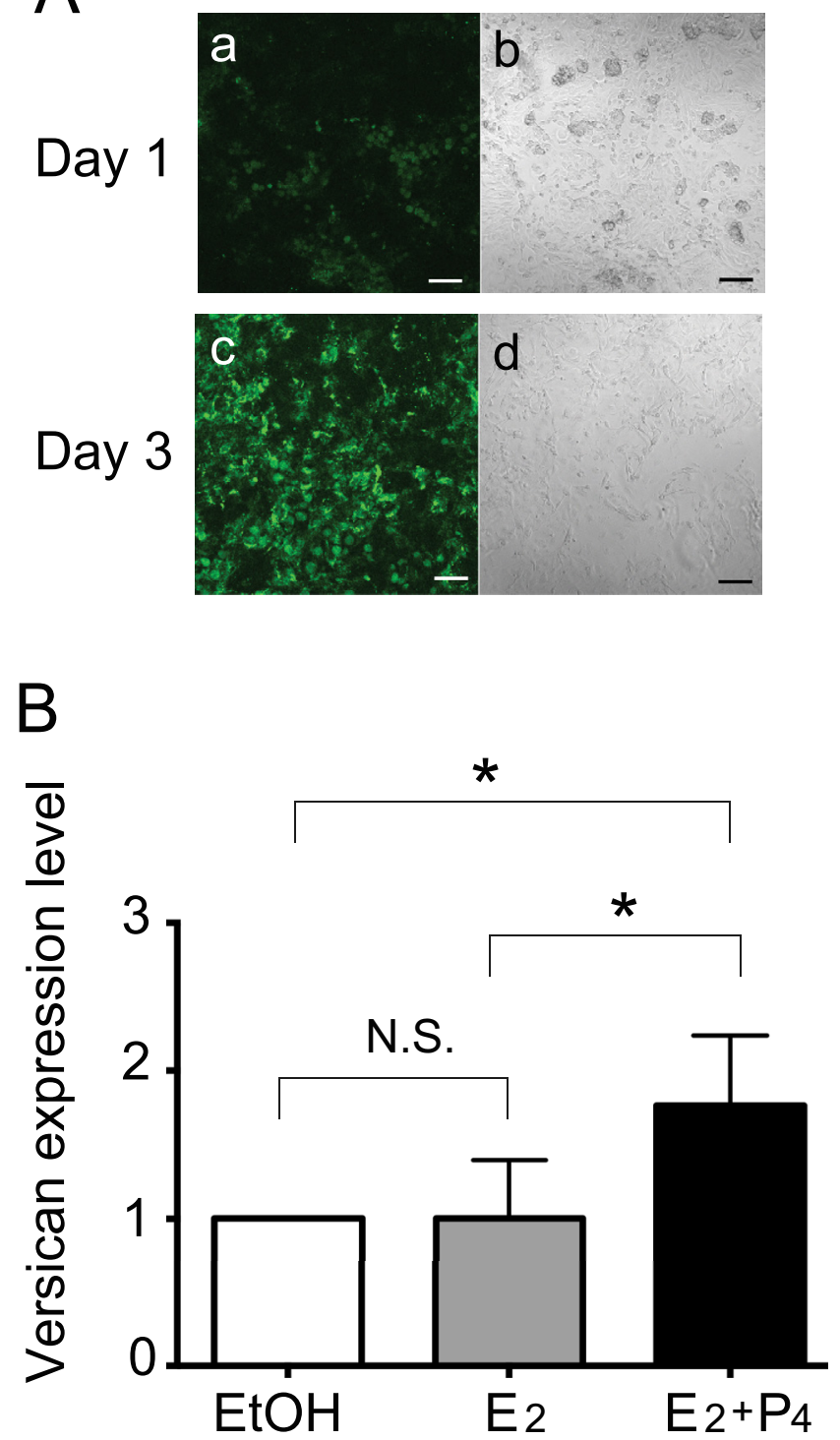

Figure 4 Effects of ovarian steroid hormones on versican expression in isolated EECs. (A) EECs were isolated from the endometrial tissue of cycle day 12 and cultured for $24 \mathrm{~h}$ (day 1 ) or $72 \mathrm{~h}$ (day 3). Note the intense versican deposition in the extracellular space on day 3 , indicating that versican secretion from EECs increased in a time-dependent manner. $(a, c)$ and $(b, d)$ represent immunofluorescence and phase-contrast images, respectively. Scale bars $=100 \mu \mathrm{m}$. (B) Isolated EECs were treated with ethanol $(\mathrm{EtOH}), 10 \mathrm{nM}$ estradiol $\left(\mathrm{E}_{2}\right)$ or $10 \mathrm{nM} \mathrm{E}_{2}$ plus $1 \mu \mathrm{M}$ progesterone $\left(\mathrm{P}_{4}\right)$ and then immunostained. The final

concentration of $\mathrm{EtOH}$ was $0.1 \%(\mathrm{v} / \mathrm{v})$. Versican expression levels in EECs were measured by mean fluorescent intensity. The sum of the integrated densities from five areas (central, upper, lower, right and left) in the immunostained specimen is defined as the 'versican expression level'. The versican expression level was significantly higher after treatment with $E_{2}$ and $P_{4}\left(E_{2}+P_{4}\right)$ than after treatment with $\mathrm{EtOH}$ or $\mathrm{E}_{2}$ alone $(n=5)$. Error bars represent standard deviation. ${ }^{*} P<0.05$. monolayer was significantly larger than those attached to the control ISKW-GFP monolayer (Fig. 6B). In contrast, the number of BeWo spheroids directly attached to the ISKW-V3 monolayer was not significantly different from those attached to the control ISKW-GFP monolayer (Fig. 6C).

\section{Chondroitin sulfate side chains are required for enhancement of BeWo spheroid attachment to ISKW monolayers}

The addition of V1-CM derived from ISKW-V1 cells significantly enhanced the number of BeWo spheroids attached to the ISKW monolayer (Fig. 7A). This attachment-promoting effect of $\mathrm{V} 1-\mathrm{CM}$ was completely abrogated when it was pretreated with chondroitinase $A B C$ (Fig. 7B). On the other hand, pretreatment with hyaluronidase did not affect the attachment-promoting effect of V1-CM (Fig. 7C).

\section{Discussion}

In this study, we investigated in vivo expression and in vitro function of versican in the human endometrium to test the hypothesis that endometrial versican is involved in human embryo implantation. All endometrial tissue samples were obtained from patients undergoing hysterectomy for benign diseases including adenomyosis, uterine fibroids or cervical carcinomas in situ. The endometrium was histologically examined to exclude the possibility of any endometrial lesions.

In our RT-PCR analysis, all versican isoforms were detectable in the human endometrium. On the other hand, Yamaguchi et al. (2006) reported that versican V2 mRNA was not expressed in the endometrium by RT-PCR analysis using the same primers as in our study. The versican V2 isoform is mostly found in the central nervous system but has been found in other tissues as well (Zimmermann \& Dours-Zimmermann 2008). As PCR amplification efficiency and linearity are different among different PCR primer sets, it would not be appropriate to compare the amount of PCR product among the four versican isoforms; however, it is possible that expression levels of versican V2 in the human endometrium is relatively lower than that of the other three isoforms. In immunohistochemistry, the antibody specific for versican V0 and V1 isoforms was used and versican was found expressed in both EECs and ESCs throughout the menstrual cycle, but not in the postmenopausal endometrium (data not shown). Western blotting using the same antibody as for immunohistochemistry revealed that EECs of various menstrual cycle phases yielded multiple proteins of uneven signal intensities ranging from 440 to $500 \mathrm{kDa}$; this range corresponds to the multiple glycosylation variants of the $\mathrm{V} 1$ isoform 
A

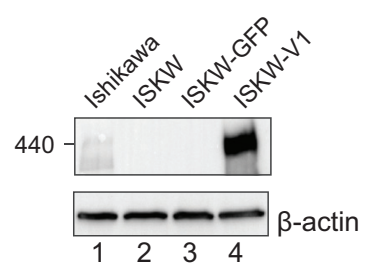

C

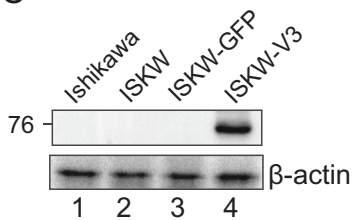

E
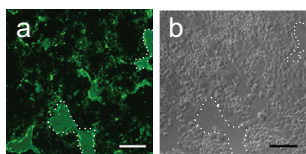

B

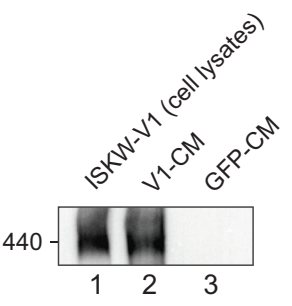

D

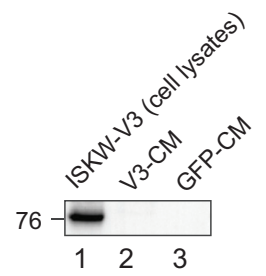

$\mathrm{F}$

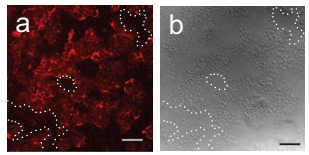

Figure 5 Characterization of versican V1- and V3-overexpressing Ishikawa cells. (A) Cell lysates extracted from original Ishikawa cells (Ishikawa; lane 1), platform Ishikawa cells (ISKW; lane 2), GFPoverexpressing Ishikawa cells (ISKW-GFP; lane 3) and versican V1-overexpressing Ishikawa cells (ISKW-V1; lane 4) were subjected to western blotting. ISKW possesses a specific sequence into which foreign DNA can be inserted by a recombinase. An intense protein signal at $440 \mathrm{kDa}$ corresponding to versican V1 is only detectable in ISKW-V1. (B) Cell lysates from ISKW-V1 (lane 1), conditioned medium derived from ISKW-V1 (V1-CM; lane 2) and conditioned medium derived from ISKW-GFP (GFP-CM; lane 3) were subjected to western blotting using the same anti-versican antibody as in (A). Note that the protein signal at $440 \mathrm{kDa}$ is detected in both ISKW-V1 cell lysates (lane 1) and V1-CM (lane 2). (C) Cell lysates extracted from original Ishikawa cells (Ishikawa; lane 1), platform Ishikawa cells (ISKW; lane 2), GFP-overexpressing Ishikawa cells (ISKW-GFP; lane 3), and versican V3-overexpressing Ishikawa cells (ISKW-V3; lane 4) were subjected to western blotting using an anti-versican monoclonal antibody raised against the G3 domain common in all versican isoforms. An intense protein signal at $76 \mathrm{kDa}$ corresponding to versican V3 was only detected in ISKW-V3. (D) Cell lysates from ISKW-V3 (lane1), conditioned medium derived from ISKW-V3 (V3-CM; lane2) and CM derived from ISKW-GFP (GFP-CM; lane 3) were subjected to western blotting using the same anti-versican antibody as in (C). Note that the protein signal at $76 \mathrm{kDa}$ is only detectable in the ISKW-V3 cell lysates (lane 1) but not in V3-CM (lane 2). (E) ISKW-V1 cells cultured for $48 \mathrm{~h}$ were subjected to immunocytochemistry using the same anti-versican antibody as in (A). Note that intense immunoreactive versican is detected not only on the cell surface but also in the extracellular space (circumscribed with the dotted line). Images (a) and (b) represent immunofluorescence and phase-contrast images, respectively. Scale bars $=100 \mu \mathrm{m}$. (F) ISKW-V3 cells cultured for $48 \mathrm{~h}$ were subjected to immunocytochemistry using anti-versican polyclonal antibody raised against the G1 domain common in all versican isoforms. Note that intense immunoreactive versican is detected exclusively on the cell surface and not in the extracellular space (circumscribed with the dotted line). Images (a) and (b) represent immunofluorescence and phase-contrast images, respectively. Scale bars $=100 \mu \mathrm{m}$.

A
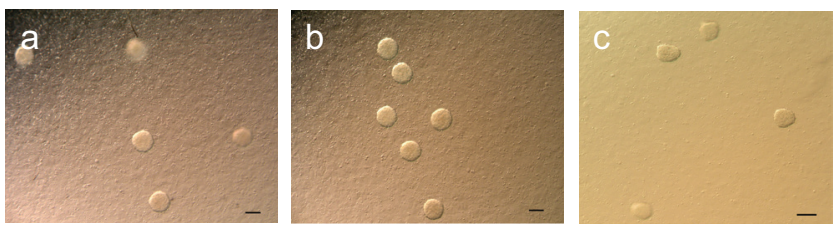

B

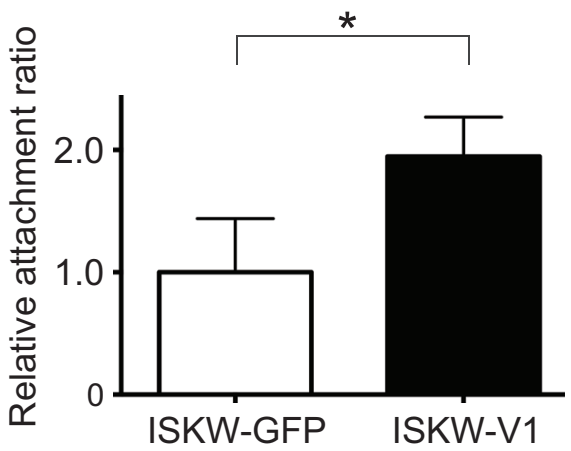

C

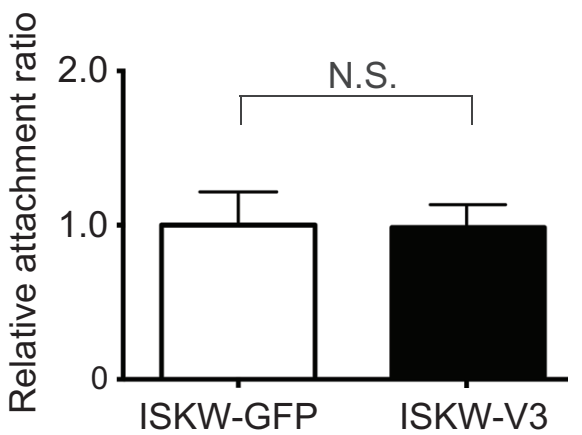

Figure 6 Differential effects of versican $\mathrm{V} 1$ and $\mathrm{V} 3$ on BeWo spheroid attachment. (A) Phase-contrast images of BeWo spheroids after 1-h incubation on a monolayer of (a) GFP-overexpressing Ishikawa cells (ISKW-GFP), (b) versican V1-overexpressing Ishikawa cells (ISKW-V1) and (c) versican V3-overexpressing Ishikawa cells (ISKW-V3). Note that all spheroids were attached to the (b) ISKW-V1 monolayer, whereas some spheroids were floating (arrowheads) over the (a) ISKW-GFP and (c) ISKW-V3 monolayers. Scale bars $=200 \mu \mathrm{m}$. (B) Attachment ratios to the ISKW-V1 monolayer $(n=4)$ were significantly higher compared with that of the control ISKW-GFP monolayer $(n=4)$. (C) Attachment ratios to the ISKW-V3 monolayer $(n=6)$ were not significantly different than those of the control $(n=6)$. All values are relative to the control, ISKW-GFP. In all panels, error bars represent standard deviation. ${ }^{*} P<0.05$; N.S., not significant.

(Mazzucato et al. 2002, Perissinotto et al. 2000), indicating that the immunoreactive signals observed in immunohistochemistry represent the $\mathrm{V} 1$ isoform. Versican V0 was not detected through western blotting, leading us to speculate that this isoform is mainly expressed in ESCs. Although we could not achieve detailed comparisons of versican expression patterns during each secretory phase due to limited amounts of sample, we were able to conclude that versican $\mathrm{V} 1$ expression and secretion in EECs peak during the 

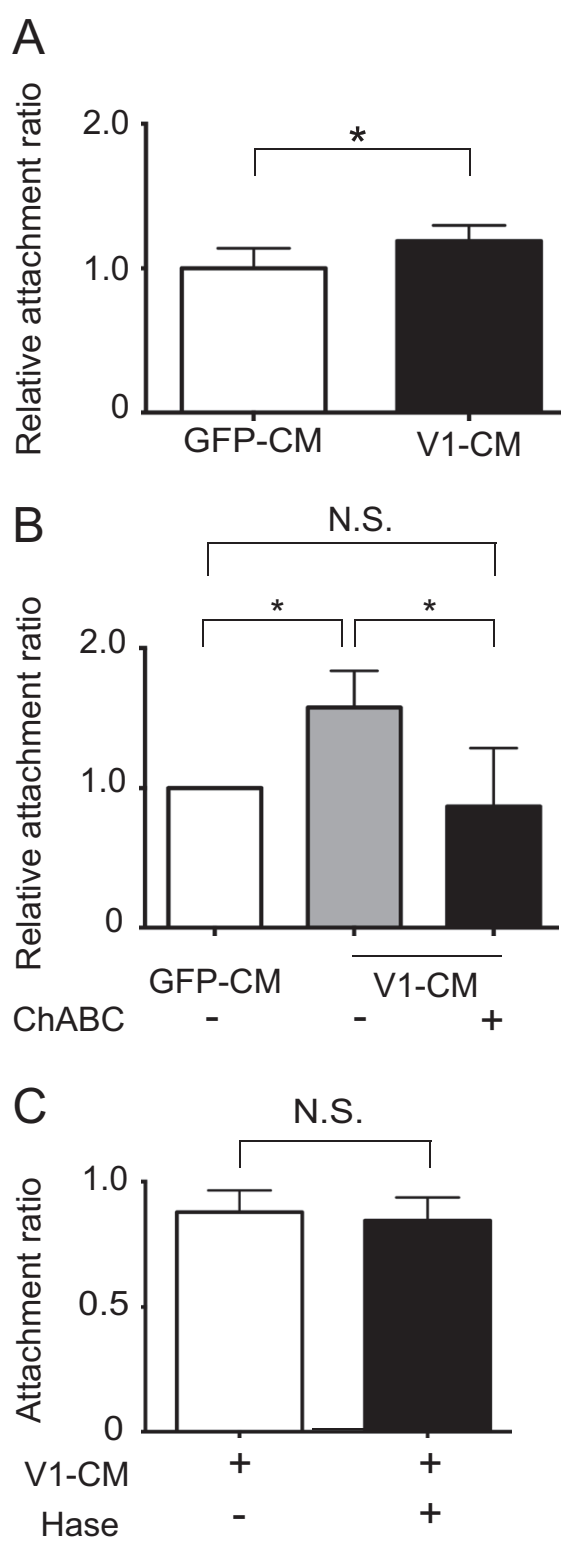

Figure 7 Versican $\mathrm{V} 1$ promotion of BeWo spheroid attachment requires the presence of chondroitin sulfate side chains. (A) BeWo spheroids are incubated on the monolayer of platform Ishikawa cells (ISKW) in the presence of conditioned medium derived from GFP-overexpressing Ishikawa cells (GFP-CM) or that derived from versican V1-overexpressing Ishikawa cells (V1-CM). The attachment ratio is significantly higher in the presence of V1-CM $(n=6)$ than in the presence of GFP-CM $(n=6)$. All values are relative to the control, GFP-CM. (B) BeWo spheroids were incubated on ISKW monolayers in the presence of GFP-CM or V1-CM with or without chondroitinase $\mathrm{ABC}(\mathrm{Ch} A \mathrm{BC})$ pretreatment. The attachment ratio significantly increased in the presence of $\mathrm{V} 1-\mathrm{CM}(n=7)$ compared with that of GFP-CM $(n=7)$. Note that the attachmentpromoting effect of $\mathrm{V} 1-\mathrm{CM}$ was completely abrogated by $\mathrm{ChABC}$ pretreatment $(n=7)$. All values are relative to the control, GFP-CM, without ChABC treatment. (C) BeWo spheroids were incubated on ISKW monolayers in the presence of $\mathrm{V} 1-\mathrm{CM}$ with or without hyaluronidase (Hase) pretreatment. Note that Hase pretreatment did not affect the attachment ratio that was increased by untreated V1-CM $(n=4)$. In all panels, error bars represent standard deviation. ${ }^{*} P<0.05$; N.S., not significant. mid-secretory phase, corresponding to the embryo implantation window (Cha et al. 2012).

Many EEC secretory proteins regulated by ovarian steroids have been implicated in the process of embryo implantation (Bell et al. 1986, Seppala et al. 1994). We demonstrated that immunoreactive signals for versican $\mathrm{V} 1$ in EECs were not affected by estradiol treatment alone, but significantly increased after treatment with estradiol and progesterone together. In mice, uterine versican is regulated by ovarian steroids (Salgado et al. 2009) and accumulates in the endometrium during the peri-implantation period (San Martin et al. 2003), suggesting a supporting role during embryo implantation. Moreover, bioinformatic analysis revealed that versican mRNA levels in goats were significantly higher in receptive endometria than in pre-receptive ones, suggesting that versican is possibly involved in the development of endometrial receptivity (Zhang et al. 2015) and that versican is a novel player in human embryo-endometrium interactions (Altmae et al. 2012). These findings indicate that versican V1 may be an important ECM component that mediates human embryo implantation.

Consequently, the possible roles of versican during human embryo implantation were investigated. The attachment-enhancing effect of BeWo spheroids was observed for versican V1, but not V3. Such isoform specificity is likely to be attributable to the structural differences between versican $\mathrm{V} 1$ and $\mathrm{V} 3$, i.e., the V3 isoform lacks glycosaminoglycan domains and chondroitin sulfate side chains. Western blotting and immunocytochemistry analyses demonstrated that secreted versican $V 1$ is released into the surrounding environment in its soluble form whereas secreted versican V3 is more likely to remain anchored to the cell surface. A similar phenomenon was described for brevican, another member of the chondroitin sulfate proteoglycan family in rats. Brevican has two isoforms translated from alternatively processed transcripts of the same gene. One isoform is secreted into the extracellular space, whereas the other remains attached to the cell membrane via glycosylphosphatidylinositol (GPI) anchors (Seidenbecher et al. 1995).

To examine the importance of versican V1-linked chondroitin sulfate side chains, versican V1-rich conditioned medium was pretreated with chondroitinase $\mathrm{ABC}$. The attachment-enhancing effect of $\mathrm{V} 1-\mathrm{CM}$ was largely abrogated after this pretreatment, indicating that chondroitin sulfate side chains are required for the attachment-enhancing effect of versican V1. This is the first study to demonstrate the importance of versican chondroitin sulfate side chains in mediating cell-cell attachment. However, chondroitinase ABC was shown to degrade not only chondroitin sulfate but also hyaluronan (Grondahl et al. 2011). There is accumulating evidence that hyaluronan, a major ECM component that interacts with versican, promotes embryo implantation 
(Chun et al. 2016). In our study, pretreatment with Streptomyces hyaluronidase did not affect the attachmentenhancing effect of versican V1. We suspect the possible reason for this inconsistency is inherent in the culture conditions ( $1 \%$ FCS) of our experimental system, which contained almost no hyaluronan. This is supported by the finding that hyaluronidase treatment of GFP-CM did not affect the attachment of BeWo spheroids.

The molecular mechanisms behind versican promotion of BeWo spheroid attachment onto the Ishikawa monolayers were not elucidated in this study. Perlecan, a heparan sulfate proteoglycan (HSPG), surrounds blastocysts after hatching and has been suggested to play a role in human blastocyst attachment. Perlecan acts as a bridge between the trophoblast and luminal epithelial cells by binding certain adhesion molecules expressed on the luminal epithelium and trophectoderm (Kimber \& Spanswick 2000). In this respect, we suspect that possible interactions between versican and specific adhesion molecules may contribute to the observed promotion of BeWo attachment to Ishikawa cells. It has been demonstrated that versican interacts with CD44 through its GAG chains as well as with integrin $\beta 1$ through its C-terminal domain ( $\mathrm{Wu}$ et al. 2002). Moreover, CD44 and integrin $\beta 1$ are both expressed on the surface of pre-implantation human embryos and endometrial epithelium (Kimber 2000). We confirmed that CD44 and integrin $\beta 1$ are expressed on the surface of Ishikawa and BeWo cells, respectively (data not shown). Further studies are required to elucidate the mechanisms behind the attachment-enhancing effects of versican $\mathrm{V} 1$.

There are several limitations to our in vitro model. First, we used human carcinoma-derived endometrial cells, which are luminal epithelial-like cells. In this regard, the observed cellular potential may not fully recapitulate that of actual EECs. Ishikawa cells, however, have been reported as a suitable alternative model for investigating human embryo implantation (Uchida et al. 2012, Cheng et al. 2017) and thus for analyzing the function of versican $\mathrm{V} 1$. Ishikawa cells retain mixed characteristics of glandular and luminal epithelia (Mo et al. 2006) and express not only functional steroid receptors, such as estrogen and progesterone (Lessey et al. 1996), but also produce many of the enzymes and structural proteins that are found in normal endometria (Castelbaum et al. 1997). Ishikawa cells have also been shown to grow as a monolayer with uniform size and cylindrical cell shape and they form tight as well as adherent junctions (Wang et al. 2012). Furthermore, Ishikawa cells possess a capacity for trophoblast apical adhesiveness in vitro (Heneweer et al. 2005). Based on these similarities between Ishikawa cells and EECs, we consider Ishikawa cells as an appropriate model for understanding the function of versican in human EECs. The second limitation is that our in vitro monoculture system lacks the paracrine interactions that normally influence cell function and behavior in vivo. Indeed, rodent epithelial/ stromal transplantation studies show that stimulation of endometrial epithelial cell mitogenesis by estrogen is mediated through stromal cells (Cooke et al. 1997). Due to these limitations, the data obtained from our model should be regarded as hypothesis generating and future research should be aimed at developing more sophisticated human implantation models using primary endometrial cells.

In summary, we have demonstrated for the first time that versican expression in EECs is regulated by ovarian steroids and is most prominent at the mid-secretory phase, which corresponds to the embryo implantation window. In the in vitro embryo implantation model, versican V1 enhanced the attachment of BeWo spheroids to the monolayer of Ishikawa cells. From these findings, we propose that versican V1 is an ECM component that facilitates human embryo implantation. In vivo experiments, such as those using conditional knockout mice or transgenic mice with tissue-specific expression, are required to substantiate the supportive role of versican during embryo implantation.

\section{Supplementary data}

This is linked to the online version of the paper at https:// doi.org/10.1530/REP-18-0333.

\section{Declaration of interest}

The authors declare that there is no conflict of interest that could be perceived as prejudicing the impartiality of the research reported.

\section{Funding}

This research was supported by a grant from the Japan Society for the Promotion of Science (24592470).

\section{Acknowledgement}

The authors would like to thank Mizuho Takemura and Iku Sugiyama for their technical assistance.

\section{References}

Afify AM, Craig S \& Paulino AF 2006 Temporal variation in the distribution of hyaluronic acid, CD44s, and CD44v6 in the human endometrium across the menstrual cycle. Applied Immunohistochemistry and Molecular Morphology 14 328-333. (https://doi.org/10.1097/00129039200609000-00012)

Altmae S, Reimand J, Hovatta O, Zhang P, Kere J, Laisk T, Saare M, Peters M, Vilo J \& Stavreus-Evers A et al. 2012 Research resource: interactome of human embryo implantation: identification of gene expression pathways, regulation, and integrated regulatory networks. Molecular Endocrinology 26 203-217. (https://doi.org/10.1210/me.2011-1196)

Bell SC, Patel SR, Kirwan PH \& Drife JO 1986 Protein synthesis and secretion by the human endometrium during the menstrual cycle and the effect of progesterone in vitro. Journal of Reproduction and Fertility. Supplement 77 221-231. (https://doi.org/10.1530/jrf.0.0770221) 
Bilalis DA, Klentzeris LD \& Fleming S 1996 Immunohistochemical localization of extracellular matrix proteins in luteal phase endometrium of fertile and infertile patients. Human Reproduction 11 2713-2718. (https://doi.org/10.1093/oxfordjournals.humrep.a019196)

Bontekoe S, Heineman MJ, Johnson N \& Blake D 2014 Adherence compounds in embryo transfer media for assisted reproductive technologies. Cochrane Database of Systematic Reviews 2 Cd007421.

Carson DD, Rohde LH \& Surveyor G 1994 Cell surface glycoconjugates as modulators of embryo attachment to uterine epithelial cells. International Journal of Biochemistry 26 1269-1277. (https://doi.org/10.1016/0020711X(94)90096-5)

Castelbaum AJ, Ying L, Somkuti SG, Sun J, Ilesanmi AO \& Lessey BA 1997 Characterization of integrin expression in a well differentiated endometrial adenocarcinoma cell line (Ishikawa). Journal of Clinical Endocrinology and Metabolism 82 136-142.

Cattaruzza S, Schiappacassi M, Ljungberg-Rose A, Spessotto P, Perissinotto D, Morgelin M, Mucignat MT, Colombatti A \& Perris R 2002 Distribution of PG-M/versican variants in human tissues and de novo expression of isoform V3 upon endothelial cell activation, migration, and neoangiogenesis in vitro. Journal of Biological Chemistry 277 47626-47635. (https://doi.org/10.1074/jbc.M206521200)

Cha J, Sun X \& Dey SK 2012 Mechanisms of implantation: strategies for successful pregnancy. Nature Medicine 18 1754-1767. (https://doi. org/10.1038/nm.3012)

Cheng X, Liu J, Shan H, Sun L, Huang C, Yan Q, Jiang R, Ding L, Jiang Y \& Zhou J et al. 2017 Activating transcription factor 3 promotes embryo attachment via up-regulation of leukemia inhibitory factor in vitro. Reproductive Biology and Endocrinology 15 42. (https://doi.org/10.1186/ s12958-017-0260-7)

Chigusa Y, Kondoh E, Mogami H, Nishimura F, Ujita M, Kawasaki K, Fujita K, Tatsumi K \& Konishi I 2013 ATP-binding cassette transporter A1 expression is decreased in preeclamptic placentas. Reproductive Sciences 20 891-898. (https://doi.org/10.1177/1933719112468956)

Chun S, Seo JE, Rim YJ, Joo JH, Lee YC \& Koo YH 2016 Efficacy of hyaluronan-rich transfer medium on implantation and pregnancy rates in fresh and frozen-thawed blastocyst transfers in Korean women with previous implantation failure. 59 201-207.

Cooke PS, Buchanan DL, Young P, Setiawan T, Brody J, Korach KS, Taylor J, Lubahn DB \& Cunha GR 1997 Stromal estrogen receptors mediate mitogenic effects of estradiol on uterine epithelium. PNAS 94 6535-6540. (https://doi.org/10.1073/pnas.94.12.6535)

Dours-Zimmermann MT \& Zimmermann DR 1994 A novel glycosaminoglycan attachment domain identified in two alternative splice variants of human versican. Journal of Biological Chemistry 269 32992-32998.

Grondahl F, Tveit H, Akslen-Hoel LK \& Prydz K 2011 Easy HPLC-based separation and quantitation of chondroitin sulphate and hyaluronan disaccharides after chondroitinase ABC treatment. Carbohydrate Research 346 50-57. (https://doi.org/10.1016/j.carres.2010.10.025)

Hamilton G 1998 Multicellular spheroids as an in vitro tumor model. Cancer Letters 131 29-34. (https://doi.org/10.1016/S0304-3835(98)00198-0)

Hannan NJ, Paiva P, Dimitriadis E \& Salamonsen LA 2010 Models for study of human embryo implantation: choice of cell lines? Biology of Reproduction 82 235-245. (https://doi.org/10.1095/ biolreprod.109.077800)

Heneweer C, Schmidt M, Denker HW \& Thie M 2005 Molecular mechanisms in uterine epithelium during trophoblast binding: the role of small GTPase RhoA in human uterine Ishikawa cells. Journal of Experimental and Clinical Assisted Reproduction 2 4. (https://doi. org/10.1186/1743-1050-2-4)

Iozzo RV \& Schaefer L 2015 Proteoglycan form and function: a comprehensive nomenclature of proteoglycans. Matrix Biology $\mathbf{4 2}$ 11-55. (https://doi.org/10.1016/j.matbio.2015.02.003)

Isogai Z, Shinomura T, Yamakawa N, Takeuchi J, Tsuji T, Heinegard D \& Kimata K 1996 2B1 antigen characteristically expressed on extracellular matrices of human malignant tumors is a large chondroitin sulfate proteoglycan, PG-M/versican. Cancer Research 56 3902-3908.

Kariya M, Kanzaki H, Takakura K, Imai K, Okamoto N, Emi N, Kariya Y \& Mori T 1991 Interleukin-1 inhibits in vitro decidualization of human endometrial stromal cells. Journal of Clinical Endocrinology and Metabolism 73 1170-1174. (https://doi.org/10.1210/jcem-73-6-1170)

Kimata K, Oike Y, Tani K, Shinomura T, Yamagata M, Uritani M \& Suzuki S 1986 A large chondroitin sulfate proteoglycan (PG-M) synthesized before chondrogenesis in the limb bud of chick embryo. Journal of Biological Chemistry 261 13517-13525.

Kimber SJ 2000 Molecular interactions at the maternal-embryonic interface during the early phase of implantation. Seminars in Reproductive Medicine 18 237-253. (https://doi.org/10.1055/s-2000-12562)

Kimber SJ \& Spanswick C 2000 Blastocyst implantation: the adhesion cascade. Seminars in Cell and Developmental Biology 11 77-92. (https:// doi.org/10.1006/scdb.2000.0154)

Kosaka K, Fujiwara H, Tatsumi K, Yoshioka S, Higuchi T, Sato Y, Nakayama T \& Fujii S 2003 Human peripheral blood mononuclear cells enhance cell-cell interaction between human endometrial epithelial cells and BeWo-cell spheroids. Human Reproduction 18 19-25. (https:// doi.org/10.1093/humrep/deg002)

Kresse H \& Schonherr E 2001 Proteoglycans of the extracellular matrix and growth control. Journal of Cellular Physiology 189 266-274. (https://doi. org/10.1002/jcp.10030)

Lane M, Maybach JM, Hooper K, Hasler JF \& Gardner DK 2003 Cryosurvival and development of bovine blastocysts are enhanced by culture with recombinant albumin and hyaluronan. Molecular Reproduction and Development 64 70-78. (https://doi.org/10.1002/mrd.10210)

Lessey BA, Ilesanmi AO, Castelbaum AJ, Yuan L, Somkuti SG, Chwalisz K \& Satyaswaroop PG 1996 Characterization of the functional progesterone receptor in an endometrial adenocarcinoma cell line (Ishikawa): progesterone-induced expression of the alpha1 integrin. Journal of Steroid Biochemistry and Molecular Biology 59 31-39. (https://doi. org/10.1016/S0960-0760(96)00103-3)

Mazzucato M, Cozzi MR, Pradella P, Perissinotto D, Malmstrom A, Morgelin M, Spessotto P, Colombatti A, De Marco L \& Perris R 2002 Vascular PG-M/versican variants promote platelet adhesion at low shear rates and cooperate with collagens to induce aggregation. FASEB Journal 16 1903-1916. (https://doi.org/10.1096/fj.02-0382com)

Mo B, Vendrov AE, Palomino WA, DuPont BR, Apparao KB \& Lessey BA 2006 ECC-1 cells: a well-differentiated steroid-responsive endometrial cell line with characteristics of luminal epithelium. Biology of Reproduction 75 387-394. (https://doi.org/10.1095/biolreprod.106.051870)

Naso MF, Zimmermann DR \& Iozzo RV 1994 Characterization of the complete genomic structure of the human versican gene and functional analysis of its promoter. Journal of Biological Chemistry 269 32999-33008.

Ng KYB, Mingels R, Morgan H, Macklon N \& Cheong Y 2018 In vivo oxygen, temperature and $\mathrm{pH}$ dynamics in the female reproductive tract and their importance in human conception: a systematic review. Human Reproduction Update 24 15-34. (https://doi.org/10.1093/humupd/ dmx028)

Nishida M 2002 The Ishikawa cells from birth to the present. Human Cell 15 104-117. (https://doi.org/10.1111/j.1749-0774.2002.tb00105.x)

Noyes RW, Hertig AT \& Rock J 1950 Dating the endometrial biopsy. Fertility \& Sterility $13-25$.

Noyes RW, Hertig AT \& Rock J 1975 Dating the endometrial biopsy. American Journal of Obstetrics and Gynecology 122 262-263. (https:// doi.org/10.1016/S0002-9378(16)33500-1)

Pattillo RA \& Gey GO 1968 The establishment of a cell line of human hormone-synthesizing trophoblastic cells in vitro. Cancer Research $\mathbf{2 8}$ 1231-1236.

Perissinotto D, lacopetti P, Bellina I, Doliana R, Colombatti A, Pettway Z, Bronner-Fraser M, Shinomura T, Kimata K \& Morgelin M et al. 2000 Avian neural crest cell migration is diversely regulated by the two major hyaluronan-binding proteoglycans PG-M/versican and aggrecan. Development 127 2823-2842.

Rohde LH \& Carson DD 1993 Heparin-like glycosaminoglycans participate in binding of a human trophoblastic cell line (JAR) to a human uterine epithelial cell line (RL95). Journal of Cellular Physiology 155 185-196. (https://doi.org/10.1002/jcp.1041550124)

Salgado RM, Capelo LP, Favaro RR, Glazier JD, Aplin JD \& Zorn TM 2009 Hormone-regulated expression and distribution of versican in mouse uterine tissues. Reproductive Biology and Endocrinology 7 60. (https:// doi.org/10.1186/1477-7827-7-60)

San Martin S, Soto-Suazo M \& Zorn TM 2003 Distribution of versican and hyaluronan in the mouse uterus during decidualization. Brazilian Journal of Medical and Biological Research 36 1067-1071. (https://doi. org/10.1590/S0100-879X2003000800013)

San Martin S, Soto-Suazo M \& Zorn TM 2004 Perlecan and syndecan-4 in uterine tissues during the early pregnancy in mice. American Journal 
of Reproductive Immunology 52 53-59. (https://doi.org/10.1111/j.16000897.2004.00182.x)

Seidenbecher Cl, Richter K, Rauch U, Fassler R, Garner CC \& Gundelfinger ED 1995 Brevican, a chondroitin sulfate proteoglycan of rat brain, occurs as secreted and cell surface glycosylphosphatidylinositolanchored isoforms. Journal of Biological Chemistry 270 27206-27212. (https://doi.org/10.1074/jbc.270.45.27206)

Seppala M, Koistinen R \& Rutanen EM 1994 Uterine endocrinology and paracrinology: insulin-like growth factor binding protein-1 and placental protein 14 revisited. Human Reproduction 9 917-925. (https://doi. org/10.1093/oxfordjournals.humrep.a138617)

Shinomura T, Nakamura S, Ito K, Shirasawa S, Hook M \& Kimura JH 2008 Adsorption of follicular dendritic cell-secreted protein (FDC-SP) onto mineral deposits. Application of a new stable gene expression system. Journal of Biological Chemistry 283 33658-33664. (https://doi. org/10.1074/jbc.M800719200)

Sobue M, Nakashima N, Fukatsu T, Nagasaka T, Fukata S, Ohiwa N, Nara Y, Ogura T, Katoh T \& Takeuchi J 1989 Production and immunohistochemical characterization of a monoclonal antibody raised to proteoglycan purified from a human yolk sac tumour. Histochemical Journal 21 455-460. (https://doi.org/10.1007/BF01845795)

Stojkovic M, Kolle S, Peinl S, Stojkovic P, Zakhartchenko V, Thompson JG, Wenigerkind H, Reichenbach HD, Sinowatz F \& Wolf E 2002 Effects of high concentrations of hyaluronan in culture medium on development and survival rates of fresh and frozen-thawed bovine embryos produced in vitro. Reproduction 124 141-153. (https://doi.org/10.1530/ rep.0.1240141)

Takahashi Y, Kuwabara H, Yoneda M, Isogai Z, Tanigawa N \& Shibayama Y 2012 Versican G1 and G3 domains are upregulated and latent transforming growth factor-beta binding protein-4 is downregulated in breast cancer stroma. Breast Cancer 19 46-53. (https://doi.org/10.1007/ s12282-011-0264-7)

Tani H, Sato Y, Ueda M, Miyazaki Y, Suginami K, Horie A, Konishi I \& Shinomura T 2016 Role of versican in the pathogenesis of peritoneal endometriosis. Journal of Clinical Endocrinology and Metabolism 101 4349-4356. (https://doi.org/10.1210/jc.2016-2391)

Uchida H, Maruyama T, Nishikawa-Uchida S, Oda H, Miyazaki K, Yamasaki A \& Yoshimura Y 2012 Studies using an in vitro model show evidence of involvement of epithelial-mesenchymal transition of human endometrial epithelial cells in human embryo implantation. Journal of Biological Chemistry 287 4441-4450. (https://doi.org/10.1074/jbc. M111.286138)

Vincent S, Marty L \& Fort P 1993 S26 ribosomal protein RNA: an invariant control for gene regulation experiments in eucaryotic cells and tissues. Nucleic Acids Research 21 1498. (https://doi.org/10.1093/nar/21.6.1498)

Wang H, Pilla F, Anderson S, Martinez-Escribano S, Herrer I, MorenoMoya JM, Musti S, Bocca S, Oehninger S \& Horcajadas JA 2012 A novel model of human implantation: 3D endometrium-like culture system to study attachment of human trophoblast (Jar) cell spheroids. Molecular Human Reproduction 18 33-43. (https://doi.org/10.1093/molehr/ gar064)

Wasa J, Nishida $Y$, Shinomura T, Isogai Z, Futamura N, Urakawa H, Arai E, Kozawa E, Tsukushi S \& Ishiguro N 2012 Versican V1 isoform regulates cell-associated matrix formation and cell behavior differentially from aggrecan in Swarm rat chondrosarcoma cells. International Journal of Cancer 130 2271-2281. (https://doi.org/10.1002/ijc.26230)

Wight TN 2002 Versican: a versatile extracellular matrix proteoglycan in cell biology. Current Opinion in Cell Biology 14 617-623. (https://doi. org/10.1016/S0955-0674(02)00375-7)

Wight TN, Kinsella MG, Evanko SP, Potter-Perigo S \& Merrilees MJ 2014 Versican and the regulation of cell phenotype in disease. Biochimica et Biophysica Acta 1840 2441-2451.

Wu Y, Chen L, Zheng PS \& Yang BB 2002 beta 1-Integrin-mediated glioma cell adhesion and free radical-induced apoptosis are regulated by binding to a C-terminal domain of PG-M/versican. Journal of Biological Chemistry 277 12294-12301. (https://doi.org/10.1074/jbc. M110748200)

Wu YJ, La DP Pierre, Wu J, Yee AJ \& Yang BB 2005 The interaction of versican with its binding partners. Cell Research 15 483-494. (https:// doi.org/10.1038/sj.cr.7290318)

Yamaguchi T, Kitaya K, Daikoku N, Yasuo T, Fushiki S \& Honjo H 2006 Potential selectin L ligands involved in selective recruitment of peripheral blood CD16(-) natural killer cells into human endometrium. Biology of Reproduction 74 35-40. (https://doi.org/10.1095/biolreprod. 105.045971)

Zako M, Shinomura T, Ujita M, Ito K \& Kimata K 1995 Expression of PG$M(V 3)$, an alternatively spliced form of PG-M without a chondroitin sulfate attachment in region in mouse and human tissues. Journal of Biological Chemistry 270 3914-3918. (https://doi.org/10.1074/ jbc.270.8.3914)

Zhang L, An XP, Liu XR, Fu MZ, Han P, Peng JY, Hou JX, Zhou ZQ, Cao BY \& Song YX 2015 Characterization of the transcriptional complexity of the receptive and pre-receptive endometria of dairy goats. Scientific Reports 5 14244. (https://doi.org/10.1038/srep14244)

Zimmermann DR \& Dours-Zimmermann MT 2008 Extracellular matrix of the central nervous system: from neglect to challenge. Histochemistry and Cell Biology 130 635-653. (https://doi.org/10.1007/s00418-008-0485-9)

Received 25 June 2018

First decision 2 August 2018

Revised manuscript received 18 September 2018

Accepted 25 October 2018 